\title{
Asynchronous replication of allelic loci in Down syndrome
}

\author{
A liza A miel ${ }^{1}$, Lydia A vivi ${ }^{2}$, Elena $G$ aber $^{1}$ and M oshe D Fejgin ${ }^{1}$ \\ ${ }^{1} \mathrm{G}$ enetic Institute, M eir H ospital, $\mathrm{K}$ far-Saba \\ ${ }^{2}$ D epartment of Human G enetics, Sackler School of M edicine, Tel-A viv, I srael
}

\begin{abstract}
We have used FISH to determine the level of sychronisation in replication timing of four pairs of alleles, unrelated to chromosome 21 (p53, HER2, RB1, and $c-m y c$ ), in foetal (amniotic fluid) cell samples of Down syndrome and in normal foetuses. All samples derived from the Down syndrome subjects showed large temporal differences in replication timing, in contrast to the high level of synchrony shown in all samples of normal individuals. Thus, as judged by four independent loci which are not associated with chromosome 21, the additional chromosome in the Down syndrome genome induces changes in the replication pattern of an allelic pair: from a synchronous pattern characteristic to concomitantly expressed alleles to an unsychronised one shown by alleles displaying an allele-specific mode of expression.
\end{abstract}

Keywords: replication timing; replication synchrony; Down syndrome; in situ hybridisation; allele-specific expression; asynchronous replication; FISH

\section{Introduction}

Replication patterns of known protein-encoding D NA sequences reveal a correlation between the specific time interval during the S-phase (of the cell cycle) at which a given DNA sequence in a given tissue is being replicated and its transcriptional status: expressed loci usually replicate early, while unexpressed ones replicate late. Hence, in many cell types, most housekeeping genes replicate early, whereas most tissue-specific genes demonstrate a differentiation-dependent pattern of replication, undergoing early replication in cells where they are expressed and late in cells where they are not expressed. ${ }^{1-3}$

Correspondence: Prof. Lydia A vivi, D epartment of $\mathrm{H}$ uman Genetics, Sackler School of Medicine, Tel-A viv U niversity, Tel-A viv 69978, I srael. Tel: 9723 6407725, 9728 9286766; Fax: 9723 6409900, 97289286665

R eceived 60 ctober 1997; revised 7 J anuary 1998; accepted 28 January 1998
The tight association between replication timing and expression is best manifested by $X$ chromosomes in cells of eutherian mammals where one $X$ chromosome (apparently for dosage compensation) is inactivated and, as such, replicates late, while its active counterpart replicates early. ${ }^{4-6}$ With the exception of $X$ chromosome loci, classical replication studies showed that homologous chromosomal segments usually replicate highly synchronously. ${ }^{7-9}$ This behaviour is in accord with the simple $M$ endelian manner where two allelic loci are expected to be expressed concomitantly.

In the past, in order to follow the replication pattern of a given DNA sequence, cell synchronisation or cell sorting was required, in addition to pre-labelling of the newly formed DNA with B rdU. R ecently, a simpler and faster method was developed, based on fluorescent in situ hybridisation (FISH), which enables determination of replication timing of allelic DNA sequences in unsynchronised cell populations. ${ }^{10}$ A ccordingly, an unreplicated DNA sequence reveals at interphase a 
single fluorescent signal (singlet; S) while a replicated sequence gives rise to a doubled signal (doublet; D). Thus, a pair of allelic loci that replicate synchronously show a high frequency of nuclei displaying two similar hybridisation signals: either two singlets (SS) or two doublets (DD). On the other hand, allelic loci which replicate asynchronously reveal a high frequency of nuclei containing two different signals, a singlet and a doublet (SD).

$U$ sing this method it was clearly shown that a pair of alleles which are known to be expressed concomitantly replicate synchronously, ${ }^{10-13}$ whilst alleles subjected to some mechanism leading to alelle-specific expression, such as imprinting, ${ }^{11,14-16} \mathrm{X}$ chromosome inactivation, ${ }^{12}$ or some other allelic inactivation, ${ }^{13,17}$ replicate asynchronously.

R ecently, using the FISH assay, ${ }^{10}$ it was shown that the replication pattern of various (non-specific) allelic loci in malignant cells was drastically changed. ${ }^{13,18,19}$ This phenomenon was attributed to the chromosomal and genetic instability associated with the cancer phenotype.

D own syndrome (trisomy-21) is the most common genetic cause of mental retardation: up to 1 in 600 newborns suffer from this syndrome. The various traits associated with Down syndrome, a multifactorial genetic disorder, have variable penetrance and expression in the Down population. ${ }^{20,21}$ In the present study we examined whether the gross genomic disturbances caused by the additional chromosome in trisomy-21 are accompanied by loss of replication control.

To test this hypothesis, we evaluated the replication patterns of four allelic loci, p53, H E R 2, R B 1 and c-myc, in foetal cell cultures derived from foetuses with $D$ own syndrome genotype and from normal ones. The p53 and HE R 2 loci were previously shown to replicate synchronously in normal cells and asynchronously in malignant cells. ${ }^{13,18}$

\section{Materials and Methods}

\section{Cell Cultures}

Fourteen human amniotic-fluid cell cultures were established following amniocentesis diagnoses. Seven cultures (samples 1-7) showed normal disomic karyotypes whilst seven others (samples 11-17) carried trisomy-21. The cells were grown in $25 \mathrm{ml}$ tissue-culture flasks (Falcon) at $37^{\circ} \mathrm{C}$ in $5 \% \mathrm{CO}_{2}$ with F10 medium (Biological Industries, Beit $\mathrm{H}$ aemek, Israel), supplemented with $20 \%$ FCS (B iological Industries, B eit Haemek, Israel), $1 \%$ glutamine, and $1 \%$ antibiotics, until approx. $3 / 4$ confluent and still actively dividing. Following exposure to colcemid (Sigma, Israel) (final concentration of
$0.2 \mu \mathrm{g} / \mathrm{ml}$ ) for two $\mathrm{h}$, cells were harvested in trypsin (Sigma, I srael), treated with $0.075 \mathrm{M} \mathrm{KCl}$ at $37^{\circ} \mathrm{C}$ for $15 \mathrm{~min}$, and washed three times with a fresh cold 3:1 methanol:acetic acid solution. The amniocyte suspensions were stored at $-20^{\circ} \mathrm{C}$ until use. A II cell samples used were taken from the original culture flasks without any passage.

\section{Slide Preparation}

Glass slides were pre-cleaned for FISH by incubation in a concentrated sulphochromic solution, rinsed with distilled water followed by two series of absolute ethanol, and then dried with a clean cloth. The stored cell suspensions were washed with a fresh cold 3:1 methanol:acetic acid solution and then dropped onto the pre-cleaned slides and air dried.

\section{Probes}

Four direct-labelled commercial probes were used, each identifying a single specific chromosome region:

(i) $\mathrm{p53}$, for chromosome region 17p13.1 (Vysis 32-190009);

(ii) HER 2, for chromosome region 17q11.2-q12 (Vysis 32-190003);

(iii) R B 1, for chromosome region 13q14 (V ysis 32-190001); and

(iv) c-myc, for chromosome region $8 q 24$ (Vysis 32 190006).

\section{In-situ hybridisation}

Fresh slide spreads were denatured for 2 min in $70 \%$ formamide $/ 2 \times \mathrm{SSC}$ at $70^{\circ} \mathrm{C}$ and dehydrated in a graded ethanol series. The probe mix was then applied to air-warmed slides ( $30 \mathrm{ml} \mathrm{mix}$ sealed under a $24 \times 50 \mathrm{~mm}$ glass cover slip) and hybridised for $18 \mathrm{~h}$ at $37^{\circ} \mathrm{C}$ in a moist chamber. Following hybridisation the slides were washed in $50 \%$ formamide/ $2 \times$ SSC for $20 \mathrm{~min}$ at $43^{\circ} \mathrm{C}$, rinsed in two changes of $2 \times \mathrm{SSC}$ at $37^{\circ}$ for $4 \mathrm{~min}$ each, and placed in $0.05 \%$ Tween 20 (Sigma, Israel). The slides were counterstained in DAPI (Sigma, I srael) antifade solution and analysed for simultaneous viewing of FITC, Texas-red and DA PI (Imagen O ptic). $M$ agnitec Imaging Processing System (Petach-Tikva, Israel) was used for FISH analysis.

\section{Cytogenetic Evaluation}

Between 54 and 140 interphase cells which showed two hybridisation signals following mono-color FISH were analysed from a sample for a given probe (Table 1). The cells were classified into three categories according to Selig et al: ${ }^{10}$

(a) cells with two singlets (SS), representing cells where both allelic loci are unreplicated (Figure 1a);

(b) cells with two doublets (DD), representing cells in which both allelic loci have replicated (Figure 1b); and

(c) cells with one singlet and one doublet (SD), revealing $\mathrm{S}$-phase cells where only one of the allelic loci has replicated (Figure 1c).

The samples were analysed 'blindly' and the frequency of cells in each category was estimated. The level of synchrony in 
Table 1 Number of cells examined in each sample following one-colour FISH for the indicated locus

\begin{tabular}{lccllll}
\hline & $\begin{array}{l}\text { Sample } \\
\text { number }\end{array}$ & Total & p53 & HER2 & RB 1 & c-myc \\
\hline Normal & 1 & 156 & 75 & 81 & - & - \\
genotype & 2 & 69 & - & 69 & - & - \\
& 3 & 153 & 58 & 95 & - & - \\
& 4 & 133 & 54 & 79 & - & - \\
& 5 & 182 & - & - & 78 & 104 \\
& 6 & 195 & - & - & 84 & 111 \\
Trisomy-21 & 7 & 257 & - & - & 140 & 117 \\
& 11 & 184 & 87 & 97 & - & - \\
& 12 & 148 & 52 & 96 & - & - \\
& 13 & 121 & 68 & 53 & - & - \\
& 14 & 136 & 81 & 55 & - & - \\
& 15 & 152 & - & - & 78 & 74 \\
& 16 & 188 & - & - & 102 & 86 \\
& 17 & 180 & - & - & 101 & 79 \\
\hline
\end{tabular}

replication timing was derived from the frequency of SD cells.

\section{Statistical Analyses}

These statistical tests were used in the analysis of the data presented in this study:

(a) The two-sample t-test and non-parametric tests were applied for testing differences between the study groups for quantitative parameters;

(b) Pearson $\chi^{2}$ and Fisher exact tests were applied to examine differences between the study groups for the categorical parameters; and

(c) the Spearman correlation was applied for testing the correlation between the study groups in other parameters examined.

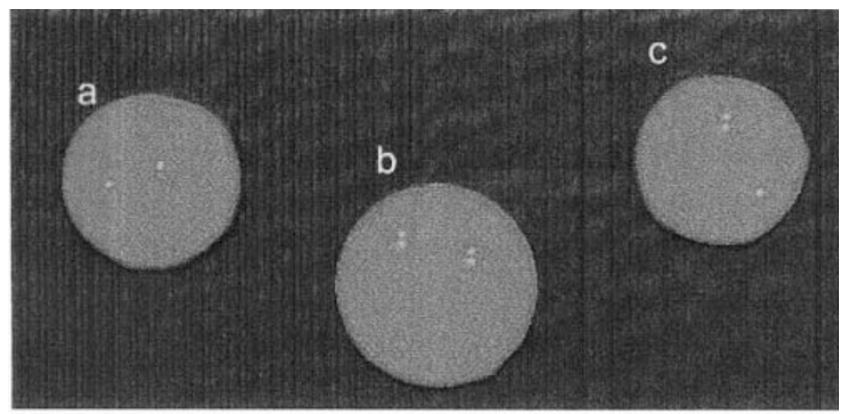

Figure 1 Hybridization signals of replicating cells at interphase following one-color FISH with a specific probe. a an interphase cell with two signals, both singlets (SS); b an interphase cell with two signals, both doublets (DD); and c an interphase cell with two signals, one singlet and one doublet (SD).
A II tests applied were two tailed, and $P$ value of $5 \%$ or less was considered statistically significant. The data were analysed using the SA S software.

\section{Results}

Following FISH with each of the four probes, p53, HER2, RB 1 and c-myc, two replication patterns of alleles were observed in interphase nuclei of cells undergoing DNA synthesis:

(i) nuclei containing two similar hybridisation signals, ie two singlets (SS) or two doublets (DD), indicating alleles at the same replication status (Figure $1 \mathrm{a}$ and Figure $1 \mathrm{~b}$ ), and

(ii) nuclei containing two different signals, ie a singlet and a doublet (SD), indicating alleles differing in their application status (Figure 1c).

For each sample, the frequency of SS, DD and SD cells was recorded.

Following FISH with the p53 and the HER 2 probes the frequencies of SD cells in samples of four normal genotypes (samples 1-4) were lower (with means of $11.0 \pm 1.2 \%$ and $10.2 \pm 1.0 \%$, respectively) than the corresponding values in four $\mathrm{D}$ own syndrome subjects (samples 11-14; means of $22.0 \pm 1.8 \%$ and $26.3 \pm 1.7 \%$, respectively; Figure 2 (i) and (ii)). The D own syndrome group differed significantly from the normal group in the level of asynchrony of the p53 $(P=0.005)$ and the HER 2 locus $(P=0.002)$.

Similarly, the frequencies of SD cells following FISH with the RB 1 and c-myc probes were notably lower in the normal group (samples 5-7) than in the Down syndrome group (samples 15-17; Figure 3 (i) and (ii)). In the normal group the mean value for RB 1 was $8.9 \pm 1.8 \%$ and for c-myc $9.3 \pm 1.3 \%$; the corresponding mean values in the Down syndrome group were $23.2 \pm 0.8 \%$ and $22.7 \pm 0.6 \%$.

Within each group the inter-individual variation was low; the various samples within each group showed similar $(P>0.50)$ levels of synchrony in replication timing of a given locus (Figure 2 and Figure 3 (i) and (ii)).

Moreover, no difference $(P>0.50)$ in the frequency of SD cells was observed between the two pairs of alleles tested in a given sample. $U$ sing the combined data of p53 and HER2 (Figure 2 (iii)), and the combined data of R B 1 and c-myc (Figure 3 (iii)) for the corresponding samples, a highly significant difference $(P=0.003)$ in the level of SD cells between Down 
a

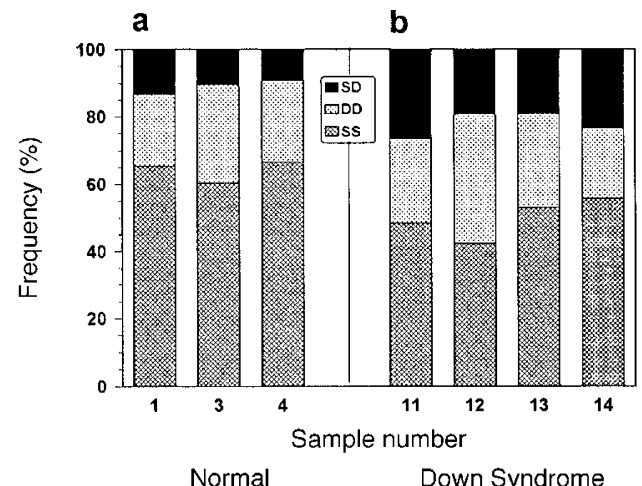

(i) $p 53$

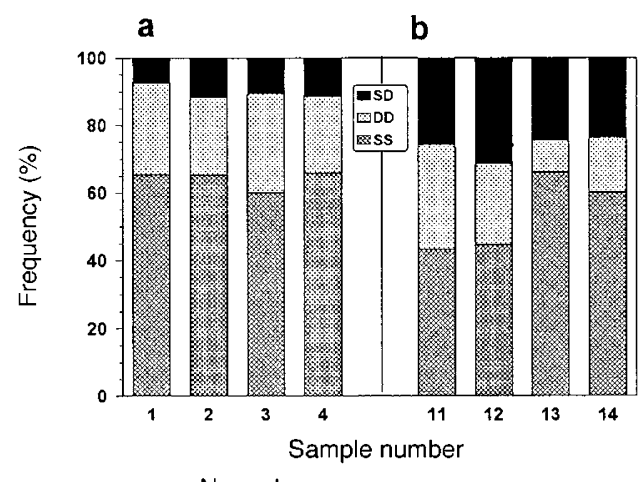

Normal

(ii) HER2

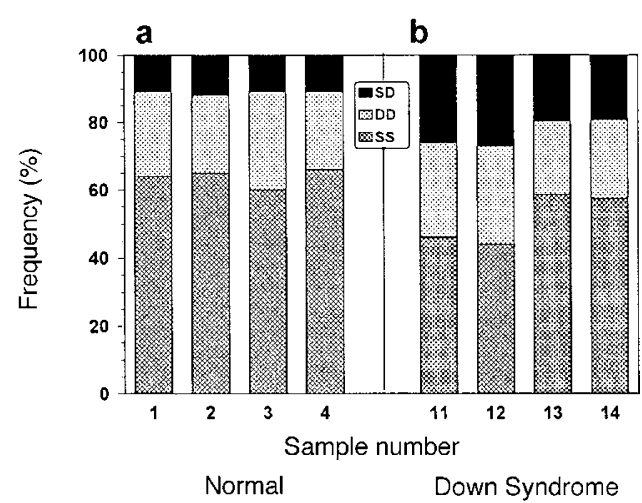

(iii) mean of p53 and HER2

Figure 2 Replication timing of p53, HER2, and mean of both allelic loci in amniotic fluid cells. a N ormal genotypes (samples 1-4), and b D own syndrome genotypes (samples 11-14). Two single hybridisation signals (SS) represent cells where both loci did not replicate yet; two double hybridisation signals (DD) represent cells where both loci replicated; and a single and a double hybridisation signal (SD) represent cells in which one locus did not replicate yet and the other one did. The frequency (\%) of each group of cells was calculated from the total population of cells revealing two hybridisation signals following one-colour FISH. The total number of cells examined from each sample for a given probe is listed in Table 1 . Note the difference in the frequency of SD cells between the samples in $\mathbf{a}$ and $\mathbf{b}$.

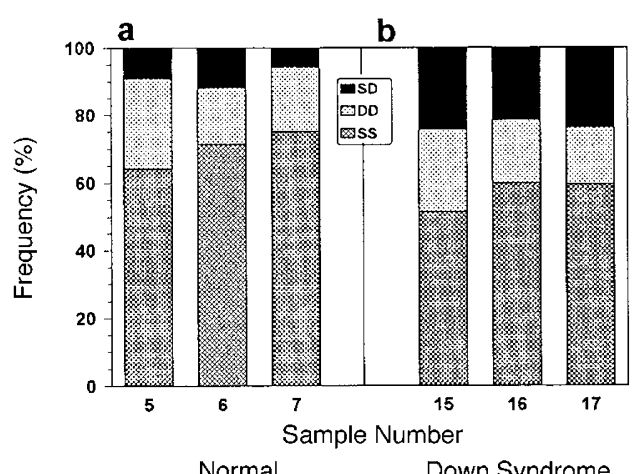

(i) RBI

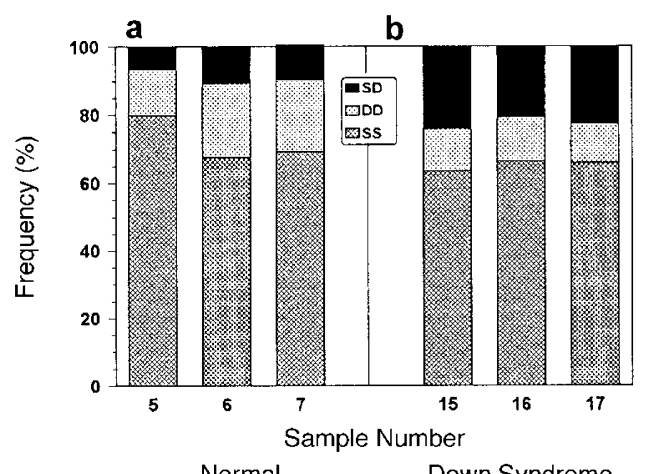

(ii) c-myc

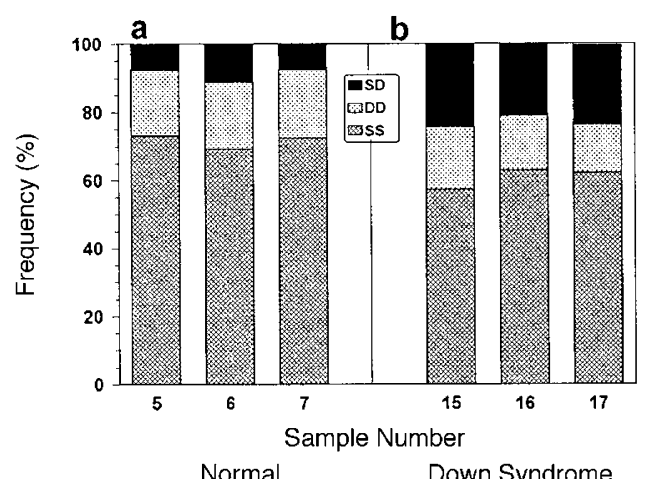

(iii) mean of RBI and c-myc

Figure 3 Replication timing of R B 1 c-myc and mean of both allelic loci in amniotic fluid cells. a N ormal genotypes (samples 5-7), and b D own syndrome genotypes (samples 15-17). Two single hybridisation signals (SS) represent cells where both loci did not replicate yet; two double hybridisation signals (DD) represent cells where both loci replicated; and a single and a double hybridisation signal (SD) represent cells in which one locus did not replicate yet and the other one did. The frequency (\%) of each group of cells was calculated from the total population of cells revealing two hybridisation signals following one-colour FISH. The total number of cells examined from each sample for a given probe is listed in Table 1 . Note the difference in the frequency of SD cells between the samples in $\mathbf{a}$ and $\mathbf{b}$. 
syndrome genotypes and normal genotypes was demonstrated. Thus, in the trisomy-21 genotypes all four pairs of alleles tested displayed an early and late replication pattern, whereas in normal genotypes all four pairs showed a synchronised pattern.

When the frequencies of SS and DD cells were examined there appeared a difference $(P=0.007)$ between the two groups of samples in the frequency of SS cells; the trisomy-21 samples showed lower levels of SS cells than normal samples (Figure 2 and Figure 3 ). This data indicate that in the Down syndrome genotypes the early replicating allele of each pair usually replicates earlier than its scheduled replication timing in a normal genome.

\section{Discussion}

We examined the replication pattern of four independent pairs of alleles, p53, HER2, RB1 and c-myc in normal disomic cells and in trisomy-21 cells derived from D own syndrome subjects. When present in disomic cells, each of the four pairs of alleles replicated highly synchronously; no differences were observed between these independent pairs of alleles. Similarly, samples from normal subjects showed no inter-individual variation in the replication pattern of alleles. That normal disomic cells show high levels of synchrony in replication timing of homologous loci was previously shown for other coding loci expressed in the expected $M$ endelian manner (see I ntroduction), as well as for the non-coding $\alpha$-satellite loci. ${ }^{19}$

In each normal sample a fraction of cells (ranging from 7.8 to $11.6 \%$ in the various samples; mean of two allelic pairs tested in each sample) showed replication asynchrony of alleles. This phenomenon is not due to temporal differences in replication timing, but rather a limitation of the FISH assay that mistakenly identifies about $10 \%$ of doublets as singlets. ${ }^{10}$ This FISH technical limitation has already been described by Lichter et $\mathrm{al}^{22}$ to explain the finding that following FISH with a specific probe around $10 \%$ of identified loci showed at metaphase hybridisation signals on one chromatid only.

In contrast to normal samples, all samples carrying trisomy-21 showed high frequencies (ranging from 21.3 to $27.0 \%$ in the various samples; mean of two allelic pairs tested in each sample) of cells with only one replicated allele, whilst its counterpart is unreplicated. This frequency should be considered high, since the frequency of cells showing the SD pattern cannot exceed that of S-phase cells in a given cell population usually around $25 \%$ in non-synchronised human cultures. ${ }^{23}$

In normal replicating cells, alleles p53, HER 2, RB 1 and c-myc displayed a pattern of replication usually shown by concomitantly expressed alleles according to the expected Mendelian manner. On the other hand, these same loci when present in cells carrying an additional chromosome-21 displayed an early and late replication pattern, similarly to alleles subjected to a process leading to mono-allelic expression. Evidently, this phenomenon is not chromosome-specific, since it was observed for p53 and HER 2 loci located on chromosome 17, for the R B 1 locus mapped to chromosome 13 and for c-myc located on chromosome 8.

From a functional point of view, mono-allelic expression due to late replication of one allele is equivalent to loss of heterozygosity ( $\mathrm{LOH}$ ) caused by allelic deletion - a common genetic instability associated with developmental abnormalities and malignancy, reviewed by Moulton et al. ${ }^{24}$ Taking into account that scheduled replication is essential for normal growth and development (see Introduction), then the loss of replication temporal control in Down syndrome foetal cells may play a role in the large phenotypic defects associated with the additional chromosome in this anomaly.

Whether the loss of replication control is specific to the dosage effect of chromosome 21 or accompanies aneuploidy in general is not yet clear. However, we have some preliminary evidence that the RB 1 alleles show an asynchronous pattern of replication in foetal cells carrying trisomy-18, and that the HER 2 alleles replicate asynchronously in cells of trisomy- 13 foetuses (work in progress). Moreover, loss of replication control was reported in cancer cells in association with loss and gain of chromosomes. ${ }^{13,19}$ It may well be possible, therefore, that chromosomal unbalanced genomes interfere with the programmed differentiationdependent replication and thus contribute to the various disorders caused by constitutional as well as sporadic aneouploidy.

\section{Acknowledgements}

We would like to thank M r G il Harari, Statistics in M edicine, Medistat Ltd, for carrying out the statistical analyses and advising us on their significance. 


\section{References}

1 G oldman M A, Holmquist G P, G ray M C, Caston LA, Nag $A$ : Replication timing of mammalian genes and middle repetitive sequences. Science 1984; 224: 686-692.

$2 \mathrm{H}$ olmquist GP: R ole of replication time in the control of tissue specific gene expression. A m J H um G enet 1987; 40: 151-173.

$3 \mathrm{H}$ atton $\mathrm{KS}, \mathrm{Dhar} \mathrm{VH}$, Brown $\mathrm{EH}$ et al: Replication program of active and inactive multigene families in mammalian cells. M ol Cell Biol 1988; 8: 2149-2158.

$4 \mathrm{G}$ artler SM, R iggs A D : M ammalian X-chromosome inactivation. A nnu Rev G enet 1983; 17: 155- 190.

5 Lyon MF: X-chromosome inactivation and the location and expression of $X$-linked genes. A $m$ J H um G enet 1988; 42: 8-16.

6 Brown CJ, Willard HF: Moleclar and genetics studies of human X-chromosome inactivation. A dv D ev Biol 1993; 2: 37-72.

7 L att SA : M icrofluorometric detection of deoxyribonucleic acid replication in human metaphase chromosomes. P ro Natl A cad Sci USA 1973; 70: 3395-3399.

8 D utrillaux B, Couturier J, R icher CL, V iegases-Pequignot $E$ : Sequence of DNA replication in $227 \mathrm{R}$ - and $\mathrm{Q}$-bands of human chromosomes using a BrdU treatment. Chromosoma 1976; 58: 51-61.

9 Drouin $R$, Lemieux $N$, Richer $C L$ : A nalysis of $D N A$ replication during $S$ phase by means of dynamic chromosome banding at high resolution Chromosoma 1990; 99: 273-280.

10 Selig S, O kumura K, Ward DC, Cedar H: D elineation of $D N A$ replication time zones by fluorescence in situ hybridisation. E M BO J 1992; 11: 1217-1225.

11 Kitsberg D, Selig S, Brandeis $M$ et al: A llele-specific replication timing of imprinted gene regions. $N$ ature 1993; 364: 459-463.

12 Boggs BA, Chinault A C: A nalysis of replication timing properties of human $\mathrm{X}$-chromosomal loci by fluorescence in situ hybridisation. Proc Natl A cad Sci USA 1994; 91: 6083-6087.
13 A miel A, Litmanovitch T, Gaber E, Lishner $M$, A vivi $L$, Fejgin $M$ : A synchronous replication of $p 53$ and $21 q 22$ loci in chronic lymphocytic leukemia. Hum G enet 1997; 101: 219-222.

$14 \mathrm{~K}$ noll JHM, Cheng SD, Lalande M : A llele specificity of DNA replication timing in the A ngelmann/Prader-Willi syndrome imprinted chromosomal region. $\mathrm{Nat} G$ enet 1994; 6: 41-46.

15 Gunaratne PH, Nakao M, Ledbetter DH, Sutcliffe JS, Chinault A C : Tissue-specific and allele-specific replication timing control in the imprinted human Prader-Willi syndrome region. G enes \& D ev 1995; 9: 808-820.

16 White $L M, R$ ogan PK, N icholls R D, Wu BL, K orf $B, K$ noll JHM : Allele specific replication of 15q11-q13 loci: a diagnostic test for uniparental disomy. A m J H um G enet 1996; 59: 423-430.

17 Chess A, Simon I, Cedar H, A xel R: A llele inactivation regulates olfactory receptor gene expression. Cell 1994; 78: 823-834.

18 A miel A, Litmanovitch $T, G$ aber $E$ et al: A synchrony in replication timing of allelic loci in bone-marrow cells derived from lymphoma and CML patients. Am J Hum G enet 1996; 59 (Suppl): A 316.

19 Litmanovitch T: Cytogenetic abnormalities observed in ovarian cancer tumors and in non-malignant cells derived from ovarian cancer patients and first degree relatives. Ph.D. thesis, Tel-A viv U niversity, 1996.

20 Shen JJ, Williams BJ, Zipursky A et al: Cytogenetic and molecular studies of D own syndrome individuals with leukemia. A m J H um G enet 1995; 56: 915-925.

21 Hernandez D, Fisher EMC: D own syndrome genetics: unraveling a multifactorial disorder. $\mathrm{H}$ um $\mathrm{Mol} \mathrm{G}$ enet 1996; 5: 1411-1416.

22 Lichter $\mathrm{P}$, Tang CC, Call $\mathrm{K}$ et al: $\mathrm{H}$ igh resolution mapping of human chromosome 11 by in-situ hybridisation with cosmid clones. Science 1990; 247: 64-69.

23 Murray AW, Hunt T: The cell cycle: an introduction. Freeman: New York, 1993.

24 M oulton $T$, Chung $W Y, Y$ uan $L$ et al: $G$ enomic imprinting and Wilms' tumor. Med Pediatr O ncol 1996; 27: 476-483. 